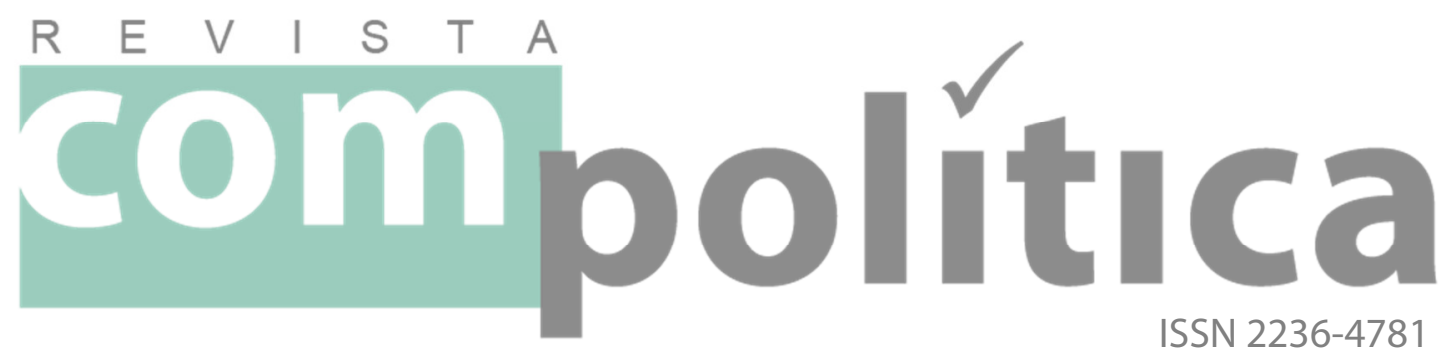

Campanhas eleitorais digitais: descobertas, desafios e transformações em mais de duas décadas de pesquisa e prática (Entrevista com Jennifer Stromer-Galley)

[Online campaigns: findings, challenges and transformations in over two decades of research and practice (Interview with Jennifer Stromer-Galley)]

ROSSINI, Patrícia Gonçalves C.

Doutoranda do Programa de Pós-Graduação em Comunicação da UFMG e pesquisadora do Grupo de Pesquisa em Mídia e Esfera Pública, EME/UFMG

IPhD Candidate from Communication Graduate Program at Minas Gerais Federal University and Media and Public Sphere Research Group associate

Entrevista realizada em novembro de 2015 por Patrícia Gonçalves Rossini, pesquisadora associada ao Grupo de Pesquisa em Mídia e Esfera Pública (EMEUFMG), por ocasião da participação de Jennifer Stromer-Galley do III Colóquio Internacional: Sistema Delibe-rativo e Mídia Interconectada.
Interview. Conducted on November 2015 by Patrícia Gonçalves Rossini, Media and Public Sphere Research Group (EME-UFMG) associate researcher, during Jennifer StromerGalley's participation on the III Colloquium: Deliberative System and Inter-Connected Media. 


\section{Campanhas eleitorais digitais: descobertas, desafios, transformações em mais de duas décadas de pesquisa e prática (Entrevista com Jennifer Strommer-Galley)}

ROSSINI, Patrícia Gonçalves C.

ampanhas eleitorais digitais têm sido objeto de interesse
acadêmico há quase três décadas. No Brasil, essa literatura ganha força a partir dos anos 2000, com a popularização do acesso à Internet em todo o país, sendo um campo promissor para pesquisadores de comunicação e política.

Desde a primeira eleição presidencial com o uso de ferramentas digitais nos Estados Unidos, em 1996, até hoje, ocorreram diversas transformações na forma como os candidatos se apropriam dessas tecnologias para atingir seus objetivos de campanha e também na maneira como cidadãos utilizam a Internet para buscar informação, participar de discussões políticas e engajar-se em campanhas eleitorais.

Jennifer Stromer-Galley figura entre as principais autoridades internacionais no assunto. Doutora pela Annemberg School for Communication da Universidade da Pensilvânia, Stromer-Galley é professora associada da Escola de Estudos da Informação da Universidade de Syracuse, nos Estados Unidos, e presidente da Association of Internet Researchers (AOIR).

Desde o início de sua carreira acadêmica, Stromer-Galley tem trabalhado com campanhas políticas online e outros fenômenos ligados ao meio digital, como conversação política e deliberação, 
além de projetos relacionados a games educacionais e de entretenimento. Seus artigos estão publicados em periódicos como o Journal of Communication, Journal of Computer-Mediated Communication, Journal of Information, Technology and Politics, New Media \& Society, Information, Communication, and Society, entre outros.

Seu livro, Presidential Campaigns in the Internet Age, publicado em 2014 pela Oxford University Press, recebeu o prêmio Roderick P. Hart de livro excepcional da divisão de Comunicação Política da National Comunication Association (NCA-EUA), em 2015. A publicação apresenta uma análise longitudinal do uso da Internet em cinco ciclos de campanhas presidenciais nos Estados Unidos, com uma abordagem histórica pioneira.

Nesta entrevista, Stromer-Galley fala sobre as transformações no uso da Internet por campanhas eleitorais nas últimas décadas, analisadas em seu livro, e discute desafios das pesquisas no campo da comunicação política e no uso de novas tecnologias.

As campanhas eleitorais online começaram, há quase três décadas, com sites muito pouco interativos e, com o passar do tempo, foram incorporando plataformas mais sociais. Há uma percepção na literatura de que o uso de mídias sociais por campanhas eleitorais contribui para tornar as campanhas mais abertas à interação e desafiam as capacidades dos candidatos de controlarem a imagem e a mensagem. Como você avalia essa mudança?

Eu gostaria de desafiar o pressuposto desta questão que diz que a Internet começou muito controlada e tornou-se social, quando, na verdade, é o oposto. No "velho oeste" da Internet em 1994, 1995 e 
1996, a web era estática, mas havia muitos elementos consideravelmente ativos. E-mails, listas de e-mail, fóruns de discussão, IRC (Internet relay chat) eram notadamente grandes para a época. Como o acesso à Internet ainda era restrito, as pessoas usando essas plataformas representavam uma porcentagem pequena da população. Mas a Internet, em sentido amplo, era essencialmente interativa. Quero dizer que o design e as tecnologias eram desenvolvidos para proporcionar canais de comunicação com uma estrutura hierárquica mínima, para que as mensagens pudessem circular na Internet mesmo na ocorrência de eventos como ataques nucleares. E é essa ausência de hierarquia que faz da Internet um meio único em relação à TV e aos outros meios de massa. Eu não posso dizer o quanto detesto o termo "mídia social", porque ele cria uma percepção incorreta de que a Internet e a web não eram sociais antes de 2008, e eu acredito que essa é uma abordagem equivocada da tecnologia e das formas como ela era usada anteriormente.

\section{Pensando nas transformações desde as primeiras campanhas digitais até as eleições mais recentes, quais são as mudanças que você observou em relação à forma como as campanhas utilizam a internet em suas estratégias?}

Em 1996 e 2000, candidatos e equipes de campanha, as estruturas da organização, vinham da era dos meios de comunicação de massa e pensavam a Internet sob uma lógica de massa. O ciclo eleitoral de 2004 é que apresenta um contraste interessante entre a maneira antiga de pensar sobre campanhas e o reconhecimento, por uma nova geração de equipes e de voluntários, de que a web poderia ser mais do que apenas um sistema de brochuras para disseminar materiais de campanha. E, então, a campanha de Howard Dean e a de 
Wesley Clark (candidatos democratas à nomeação do partido), que eram candidatos insurgentes e tinham pouco a perder, puderam experimentar novas formas de promover os candidatos, organizar e mobilizar apoiadores, encorajando-os a trabalhar juntos em prol da campanha usando ferramentas interativas da Internet. Mas a candidatura de Dean foi um desastre por muitas razões. O hype inicial para Dean foi a mensagem de oposição ao governo Bush e à guerra no Iraque, pois os democratas mainstream, como John Kerry, eram passivos em relação à guerra. Dean foi o primeiro candidato viável a endossar uma mensagem forte contra a guerra que ressoava na base democrata. Além disso, seu coordenador de campanha, Joe Trippi, era um entusiasta da tecnologia e apostou no potencial da Internet para divulgar a campanha e torná-la relevante. Então, era uma campanha interessante por ser a tempestade perfeita: o candidato certo com a mensagem certa, os contatos certos e o coordenador de campanha certo para investir em tecnologia. Mas a campanha não soube coordenar toda a energia e empolgação dos apoiadores usando as tecnologias disponíveis na época. No fim, eles perderam o controle da mensagem e perderam o controle sob as percepções que as pessoas tinham sobre o candidato, que eram construídas no blog (do candidato) sem que houvesse as correções de rumo necessárias. Logo, eu considero 2004 interessante, por representar esse embate entre interatividade e lógica de massa. E, em 2008, as campanhas começaram a compreender formas de usar plataformas digitais para canalizar a energia dos apoiadores em conformidade com seus objetivos. A ideia de interatividade controlada funciona bem em 2008 e 2012, quando os candidatos descobrem como dar abertura suficiente para que os cidadãos se sintam envolvidos com a campanha, mas sem dar liberdade em excesso para que eles pudessem agir de formas que não fossem interessantes para 0 objetivo de eleger o candidato. 
No livro, você aponta que campanhas insurgentes são mais inovadoras do que candidatos mainstream, ainda que elas tenham menos recursos, e que elas ajudam a delinear tendências para o futuro. Você diria que candidatos insurgentes têm mais liberdade para experimentar?

Olhando para as campanhas em geral, candidatos insurgentes definitivamente estão mais livres para experimentar do que incumbentes e também possuem mais liberdade para atacar oponentes e experimentar diferentes mensagens, porque eles não têm tanto a perder. Experimentar torna-se potencialmente benéfico para o insurgente, mas é arriscado para candidatos incumbentes ou majoritários. Você pode experimentar novas estratégias de comunicação e táticas de mensagem e, se elas derem errado, você pode perder apoio, receber cobertura negativa de mídia e até perder doações de campanha. Por isso, candidatos incumbentes e majoritários são notoriamente conservadores em relação às táticas de campanha.

Há um argumento que circula na literatura sugerindo que a Internet seria democratizante para candidatos com menos recursos por representar um canal de comunicação de custos relativamente baixos, se comparado aos meios massivos. Você diria que a Internet contribui para democratizar as campanhas neste sentido - ou seja, possibilitando que candidatos com menos recursos encontrem formas de divulgar ideias e propostas através dessa plataforma? 
Para responder essa pergunta é preciso fazer um estudo sistemático dos recursos financeiros dos candidatos. É uma questão complexa. Não é só sobre a Internet, mas sobre a mensagem do candidato, o seu carisma e seus contatos antes de a campanha começar. Você pode apontar para o Obama e dizer que ele não tinha nada quando se lançou candidato em 2007, enquanto Hillary Clinton tinha um verdadeiro aparato de guerra quando comparada a qualquer outro candidato democrata. Então, você pode dizer que Obama usou a Internet para se beneficiar daquela energia (dos apoiadores), mas ele tinha outras vantagens na corrida. Ele era um orador carismático. Bons políticos têm noção do clima de opinião pública e eu acredito que ele sentiu que o eleitorado queria mudança. O problema de Hillary Clinton neste aspecto era não representar essa mudança, pois ela foi senadora, primeira-dama e parte da dinastia Clinton. Assim, a candidatura de Hillary trazia um sentimento de volta ao passado para o eleitorado, também por causa de seu marido ter sido presidente, enquanto Obama representava algo novo e promissor. E raça foi parte disso também. A ideia de que os Estados Unidos poderiam estar além das questões raciais para eleger um candidato negro também corroborava para que Obama representasse a mudança que o eleitorado queria. Então, não se trata apenas de questionar como os candidatos usam as tecnologias. É preciso considerar uma série de variáveis em conjunção com aquilo que os candidatos fazem online para analisar o papel da Internet em campanhas bem-sucedidas ou fracassadas.

No livro, você enfatiza que, embora as campanhas eleitorais sejam um elemento vital da democracia, elas não são intrinsecamente democratizantes, porque falham em engajar os cidadãos em deliberações legítimas sobre problemas de governo. 
Se este é o caso, qual seria o maior impacto das tecnologias digitais nas práticas e táticas das campanhas políticas?

Doações de campanha. A quantidade de dinheiro que os candidatos têm conseguido angariar nos períodos de campanha é fenomenal e isso quebrou o sistema de financiamento de campanha nos Estados Unidos, todas as leis que regulamentam o financiamento. As formas como as campanhas angariam fundos hoje mudou dramaticamente com o uso de targetting e micro-targetting através da Internet. O microtargetting já era usado há décadas por meio do correio convencional, mas a possibilidade de criar bancos de dados enormes usando a Internet e monitorando práticas e comportamentos de usuários no site dos candidatos faz com que essa prática seja mais eficaz para arrecadar dinheiro. Por isso, o financiamento de campanha é um dos aspectos que mais sofreram transformações com o uso da Internet nos Estados Unidos.

Em que sentido - se é que há algum - você acredita que o uso da Internet por campanhas políticas pode trazer benefícios para os cidadãos?

Um ponto fraco do meu livro é não considerar a perspectiva dos cidadãos e eu realmente espero que outros pesquisadores se dediquem a pensar e compreender como é a experiência de campanha desse ponto de vista. Meu argumento crítico é que - a despeito de como os eleitores se sintam - a perspectiva das campanhas é de que os cidadãos são meios através dos quais candidatos são eleitos. A expressão que uso no livro é "peões em um tabuleiro de xadrez". Candidatos e suas equipes estão preocupados em mobilizar apoiadores para produzir ou transmitir a mensagem perfeita nas redes certas e atingir parcelas do eleitorado que 
interessam ao candidato para que ele possa se eleger. A tecnologia não é usada de maneira emancipatória, pois eles (os candidatos e as campanhas) não estão interessados em envolver os cidadãos no processo político de forma genuína. Mas é possível que os cidadãos vejam esse processo por uma perspectiva diferente. Não há pesquisas suficientes para indicar isso, mas eu adoraria saber se os cidadãos sentem sua legitimidade aumentada quando usam essas plataformas, se se sentem ouvidos, se o uso das tecnologias promove senso de confiança e eficácia nos partidos e no processo eleitoral mais amplo. Precisamos avançar a pesquisa nessa frente para compreender o significado das campanhas online para os cidadãos.

Você argumenta no livro que as affordances dos sites de redes sociais e plataformas de conteúdo compartilhado desafiam o controle das campanhas, uma vez que as pessoas podem manipular imagens e criar "memes" que atrapalham a construção de imagens e mensagens. Você diria que o uso dessas plataformas torna as campanhas mais permeáveis à medida que possibilitam a influência dos cidadãos sobre a agenda e forcem os candidatos a debater assuntos sensíveis?

Eu diria que quando cidadãos são capazes de organizar e pressionar candidatos com o uso dessas plataformas, então eles têm a chance de influenciar a agenda e as conversas que ocorrem entre eleitores, candidatos e elites. Eu precisaria refletir antes de dizer se o processo é genuinamente democratizante. Mas há uma parte de mim interessada em compreender essas relações de poder entre políticos, elites, instituições e cidadãos. Eu acredito que existam potenciais emancipatórios no uso das tecnologias digitais, mas a questão é se as pessoas as utilizam para fins emancipatórios. O que eu observo é que 
as elites políticas buscam controlar e estruturar formas de participação e interação para minimizar os impactos desses usos emancipatórios e o fazem para que possam continuar levando seus interesses adiante. Ao mesmo tempo, vejo que cidadãos, geralmente em coletivos ou movimentos ativistas, usam as affordances dos meios digitais para pressionar e desafiar os controles da elite, em tentativas de influenciar conversas mais diversificadas e pressionar agendas distintas. Então é um tipo de dança entre elites e cidadãos, que estão constantemente negociando esses relacionamentos. Para as elites, é uma questão de preservar poder, definir a mensagem e a agenda de discussão. Para os cidadãos, o objetivo é desafiar este controle e pressionar por uma abertura de agenda. Essa disputa (entre movimentos sociais, cidadãos, elites políticas) sempre existiu. O que é interessante, atualmente, são as novas possibilidades abertas pelas affordances dos canais de comunicação digitais para incrementar essa disputa.

$\mathrm{Na}$ visão de uma pesquisadora que tem estudado fenômenos de comunicação política na Internet durante toda a sua carreira, quais seriam os desafios de atuar neste campo?

Um dos desafios é que a tecnologia vive mudando e quando novos canais surgem - como o Twitter, por exemplo -, todo mundo quer estudar aquela novidade. Isso me preocupa, porque as plataformas estão sempre mudando e se você só está interessado em mensagens, discussões ou efeitos políticos no Twitter, você não sabe bem o que está acontecendo na esfera política de fato. Usuários do Twitter nos EUA, por exemplo, são apenas $20 \%$ da população online. Destes, apenas $10 \%$ são usuários ativos e uma boa parte deles são jornalistas e elites. Então, eu fico desconfiada de pesquisas que focam nessas 
plataformas sem dar um passo atrás para compreender os canais de comunicação de maneira mais ampla, porque o resultado delas representa uma imagem muito fragmentada da esfera política. Para fazer uma analogia, é o mesmo que estudar propagandas na TV na era dos meios de massa e focar a análise em apenas um canal específico, como a ABC (canal de TV norte-americano). Por que alguém faria isso? É uma abordagem que não faz muito sentido. Portanto, por que olhar apenas para o discurso político no Twitter? Parece ser uma perspectiva muito limitada sobre o que está acontecendo na esfera política. Eu adoraria ver pesquisas que não focam plataformas específicas, mas problemas e questões políticas engajamento, participação, conhecimento político -, tentando compreender o relacionamento entre campanhas e cidadãos, compreender o que desencadeia um aumento de participação, enfim, olhar para mudanças que podemos ver ou mensurar observando esses canais de comunicação digital.

\section{Por que devemos ter cautela ao abordar o potencial político das novas plataformas e tecnologias?}

O desafio é entender o que acontece na Internet como parte importante de processos ou fenômenos políticos mais amplos, o que significa que estudos focados apenas na Internet oferecem uma perspectiva limitada ou incompleta. No caso das campanhas, as propagandas de TV ainda são o destino da maior parte do orçamento. Isso me preocupa porque não vejo muitas pessoas interessadas em estudar propagandas de TV e, pelo menos nos EUA, é lá que a ação está! As estimativas para a campanha de 2016 sugerem que os gastos destinados à Internet serão de um terço a um quarto do orçamento. Logo, nós estamos deixando de olhar para o 
contexto mais amplo quando focamos apenas a Internet e, mais ainda, plataformas específicas. Se as pessoas estão mais interessadas em plataformas do que nos comportamentos, efeitos e resultados, isso é um problema. 


\section{Referências}

STROMER-GALLEY, J. Presidential Campaigning in the Internet Age. New York, NY: Oxford University Press, 2014.

STROMER-GALLEY, J.; FOOT, K. A. Citizen perceptions of online interactivity and implications for political campaign communication. Journal of Computer-Mediated Communication, v. 8, n. 1, 2002.

STROMER-GALLEY, J. On-line interaction and why candidates avoid it. Journal of Communication, v. 50, n. 4, pp. 111-132. Doi: 10.1111/j.1460-2466.2000.tb02865.x, 2000.

COMP(IITICA

ASSOCIACCÃO BRASILEIRA

DE PESQUISADORES EM

COMUNICACÃO E POLITILCA

Diretoria da Associaçâo/ Director Boara

Presidente | President

Fernando Lattman-Weltman (UERJ)

Vice-Presidente | Vice-President

Arthur Ituassu (PUC-Rio)

Secretária Executiva | Executive Secretary

Kelly Prudêncio (UFPR)

\section{Corpo Editorial / Editorial Board}

Coordenação Editorial | Editorial Coordination Alessandra Aldé (UERJ) \& Maria Helena Weber (UFRGS)

Editores Executivos | Executive Editors

Camilo Aggio (UFBA), Diógenes Lycariäo (UFC), Rafael Cardoso Sampaio (UFPR) \& Viktor Chagas (UFF)

Editoras Assistentes | Assistant Editors

Ana Angélica Soares (FGV), Fernanda Sanglard (UERJ) \& Isabele Mitozo (UFPR)
A Revista Compolítica é uma revista eletrônica da Associação Brasileira de Pesquisadores em Comunicação e Política

[Revista Compolitica is an electronic journal published by the Brazilian Association of Political Communication Scholars]

Ao citar este artigo, utilize a seguinte referência bibliográfica

[To cite this article, please use the following reference]

ROSSINI, Patrícia Gonçalves C. Campanhas eleitorais digitais: descobertas, desafios e transformações em mais de duas décadas de pesquisa e prática (Entrevista com Jennifer Stromer-Galley). In: Revista Compolítica 5 (2), 2015. 
